improvements may be explained on the basis of the general weight-loss but the bilateral mastectomy, by increasing the compliance of the chest wall, may also have contributed.

It is not considered that this case supports a policy of surgical removal of adipose tissue in all cases of obesity. It is felt, however, that such treatment, namely bilateral mastectomy in post-menopausal obese patients with large pendulous breasts and abdominal dermolipectomy, should be considered as an adjunct to dietary restriction in the grossly obese patient.

\section{Acknowledgments}

We should like to thank Mr.R. D P. Craig for operating on this patient and Mr J. W. Firth for the photographs.

\section{References}

CARroll, D. (1956) A peculiar type of cardiopulmonary failure associated with obesity. American Journal of Medicine, 21, 819.

Collison, D.R. (1967) Total fasting for up to 249 days. Lancet, i, 112.

McMullaN, J.J. (1959) Obesity and body weight in general practice. The Practitioner, 182, 222.

Silverstone, J.T. (1967) The treatment of obesity. Hospital Medicine, 1, 594.

\title{
Aplastic anaemia with carcinoma of the thyroid
}

\author{
C. C. SMITH \\ A. J. KING \\ M.B., M.R.C.P.(Ed.) \\ M.B., Ch.B.(Ed.) \\ Department of Medicine, Royal Infirmary, Edinburgh
}

APLASTIC anaemia is characterized by the occurrence of anaemia, leucopenia, and thrombocytopenia, resulting from hypocellularity of the bone marrow (Vincent \& De Gruchy, 1967). Implicit in the term, as first used by Ehrlich in 1888, is that there is no associated evidence of increased blood destruction, or of infiltrative disease of the bone marrow (Scott, Cartwright \& Wintrobe, 1958). The idiopathic condition originally described is less common than the secondary type, in which some toxic agent can be implicated (De Gruchy, 1968) and carries a worse prognosis (Vincent \& De Gruchy, 1967). Although the idiopathic type occurs at all ages it is rare in childhood (De Gruchy, 1968). The condition carries a high mortality rate, and poses many problems in management (Vincent \& De Gruchy, 1967).

The coexistence of idiopathic aplastic anaemia and malignancy is exceedingly uncommon. In one survey of malignancy and anaemia there were only two cases of aplastic anaemia in a series of sixty-five cases (Banerjee \& Narany, 1967). Leucoerythroblastic anaemia may occur where there are bone narrow metastases, while acquired autoimmune haemolytic anaemia is described in association with disseminated malignancy (De Gruchy, 1968).

Papillary adenocarcinoma is one of the more usual thyroid tumours and not infrequently occurs in children, where it carries a good prognosis (Willis, 1967; Anderson, 1967). An extensive search of the literature has failed to reveal a case of idiopathic aplastic anaemia associated with adenocarcinoma of the thyroid, without demonstrable bone marrow metastases. It is possible that the following case may be unique.

\section{Case report}

The patient, a 16-year-old grocer's assistant, was admitted to hospital in December 1968. He gave a 4-week history of malaise, tiredness, and increasing breathlessness. In the week preceding admission he had experienced daily occipital headaches and had fainted on several occasions. There was no relevant past or family history. For 12 days he had been receiving oral iron, but he denied exposure to other drugs, known toxic chemicals or radiation. He gave no history of blood loss or of a bruising tendency.

On admission he was a pale, rather overweight boy, with numerous petechiae and several purpuric haemorrhages over his trunk. He had sinus tachycardia and a BP of 160/70 without evidence of cardiac failure. The trachea was deviated to the left and a large rubbery lymph node was palpable medially in the right posterior triangle of the neck. The liver and spleen were not palpable.

Investigations: Haemoglobin $5.6 \mathrm{~g} / 100 \mathrm{ml}(39 \%)$. PCV $15 \%$, RBC 1.76 million $/ \mathrm{mm}^{3}$, reticulocytes less than $1 \%$, MCV $80 \mu^{3}$, MCHC $38 \%$; ESR $48 \mathrm{~mm}$ in first hour; WBC $4100 / \mathrm{mm}^{3}$ (neutrophils $18 \%$, lymphocytes $80 \%$, monocytes $2 \%$ ); platelets 31,000 / $\mathrm{mm}^{3}$. No immature cells were seen in the peripheral blood film. Serum iron $345 \mu \mathrm{g} / 100 \mathrm{ml}$. TIBC $420 \mu \mathrm{g} /$ $100 \mathrm{ml}$. Serum folate $13.0 \mathrm{~m} \mu \mathrm{g} / \mathrm{ml}$. Serum $B_{12}$ 
$214 \mu \mu \mathrm{g} / \mathrm{ml}$. The PBI, liver function tests, serum uric acid, serum calcium and phosphate, blood urea and electrolytes were normal, as were total plasma protein and electrophoretic pattern. No gastric or thyroid antibodies were present, and the ANF was consistently negative. Several sternal marrow aspirations produced blood only but marrow trephine biopsies revealed hypocellular marrow with a sprinkling of cells in fatty matrix. No signs of metastases or of leukaemia were evident. The chest radiograph and skeletal survey were normal. Views of the neck and thoracic inlet showed enlargement of the thyroid gland with tracheal displacement to the left. A radioactive isotope thyroid scan revealed diminished uptake in the lower pole of the right lobe as compared with the left. Marrow hypoplasia was confirmed by a prolonged ${ }^{50} \mathrm{Fe}$ clearance from plasma in association with high liver uptake. The lymph node was biopsied following platelet transfusion and histological examination showed cells from a papillary adenocarcinoma of the thyroid.

Following admission he was transfused with whole blood, and corticosteroids were begun as prednisolone $80 \mathrm{mg}$ daily. This was reduced over a month to a maintenance dose of $30 \mathrm{mg}$ daily. Repeated whole blood and platelet transfusions were required to maintain his haemoglobin and staunch profuse epistaxes, the ESR then being $83 \mathrm{~mm}$ in first hour, the platelet count below $10,000 / \mathrm{mm}^{3}$ and the WBC $3300 / \mathrm{mm}^{3}$ (neutrophils $16 \%$, lymphocytes $81 \%$, monocytes $3 \%$ ). Courses of antibiotics were given for episodes of purulent bronchitis, and as a prophylactic against intercurrent infection.

While continuing prednisolone $30 \mathrm{mg}$ daily he received daily intravenous injections of phytohaemagglutinin (PHA) $1 \mathrm{mg}$ for 7 days. This failed to produce a reticulocytosis or improvement in the neutrophil count, but caused painful thrombophlebitis at the injection sites, with systemic upset and pyrexia. It was then decided to start oxymetholone $400 \mathrm{mg}$ daily, together with thyroxine $0.1 \mathrm{mg}$ t.d.s., continuing prednisolone $30 \mathrm{mg}$ daily. This regime was continued from mid-February until his death early in April 1969, throughout which period he required repeated whole blood and platelet transfusions. No immature cells appeared in the peripheral blood and repeated marrow trephine biopsies failed to show evidence of marrow stimulation or of metastases. While on this regime he developed fluid retention and virilization.

Throughout hospitalization he suffered daily epistaxes, latterly associated with widespread purpuric haemorrhages and symptoms suggestive of pleural, pericardial and subarachnoid bleeding. In the last 2 months of his illness there were repeated incidents of haemoptysis, haematemesis and rectal bleeding. On the day prior to his death he developed severe right lower abdominal pain with haemate- $\frac{2}{3}$ mesis, melaena, and later the passage of unaltered $\frac{\Phi}{\propto}$ blood per rectum. He died from aspiration of gastrice. contents while heavily sedated with opiates.

\section{Necropsy}

This confirmed that the immediate cause of death $\frac{\overline{\bar{c}}}{\overline{\bar{s}}}$ had been aspiration of gastric contents. The peri- $\bar{\Phi}$ cardial sac contained blood-stained fluid, and haemorrhage had occurred into the lower part of the ${ }^{\infty}$ right paracolic gutter and into the wall of the $\vec{\circ}$ caecum and terminal ileum, including the sub-serous $\vec{\overrightarrow{ }}$ tissues. The trachea and bronchi were congested and ${ }_{\sigma}^{\omega}$ there was evidence of intra-alveolar bleeding. Theृ gastric mucosa was haemorrhagic, and there was 3 altered blood in the small intestine. The liver and spleen were somewhat enlarged. Marrow from the $-\mathrm{r}$ femora, vertebrae, and sternum was fatty, showing minimal haemopoietic activity. There was no evidence of metastases.

The left lobe of the thyroid was normal, but the을 right was enlarged and nodular, showing on sectiona moderately well differentiated adenocarcinoma. 3 Several right-sided cervical lymph nodes contained metastatic tumour.

\section{Discussion}

Because in younger patients the prognosis papillary adenocarcinoma of the thyroid is relatively good, therapeutic efforts were directed towards the aplastic anaemia. The percentage of patients whose aplastic anaemia undergoes spontaneous remission $\triangle$ is small (Mohler \& Leavell, 1958). Even with treat- $\overrightarrow{0}$ ment of the more favourably secondary type, only 3 some $25 \%$ will attain partial or complete remission (Scott et al., 1959). Those idiopathic cases with pro-? found neutropenia seem to carry an especially grave prognosis (Lewis, 1965).

The failure of conventional therapy with high $\frac{5}{3}$ dosage corticosteroids and repeated whole blood, packed cell, and platelet transfusions prompted $\frac{0}{3}$ attempts at marrow stimulation with phytohaemagglutinin (PHA) (Baker \& Oliver, 1965; Catovsky \& 을 Sforza, 1967; Grunewald et al., 1965; Hayes \& $\frac{D}{O}$ Spurr, 1966; Retief, Wasserman \& Hofmeyer, 1964) and oxymetholone (Sánchez-Medal, Gómez-Leal \& N Duarte-Zapata, 1966; Sánchez-Medal et al., 1964; Silink \& Firkin, 1968; Allen et al., 1968). These were tried in turn, corticosteroids being continued through- $\omega$ out to reduce the bleeding tendency.

Phytohaemagglutinin (PHA), a mucoprotein extract of the bean Phaseolus vulgaris, has been shown to have a mitosis-stimulating effect on cells in tissue + culture (Nowell, 1960). Intense mitotic activity $\frac{0}{0}$ occurs in cells of the lymphocytic and monocytic $\underset{\mathbb{D}}{\mathbb{D}}$

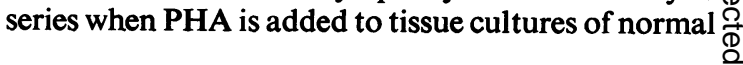


human peripheral blood cells (Cooper, Barkhan \& Hale, 1963). The drug was first used clinically by Humble in 1963, his series of six patients with secondary aplastic anaemia all showing apparent evidence of marrow stimulation.

Oxymetholone (2 - hydroxymethylene - 17 - alpha methyl-17 $\beta$ hydroxy-3 androstanone) is a synthetic anabolic derivative of testosterone with potent erythropoietic-stimulating activity. The main side effects are virilization and fluid retention, but abnormalities of liver function have been reported (Sánchez-Medal et al., 1964, 1966). It is not known in which way the hormone influences haemopoiesis. The drug was first used clinically by Sánchez-Medal and his associates who reported a $70 \%$ response in a series of eight children and fifty-four adults. Remissions, when they occurred, did so only after 2 or more months of treatment, and a favourable response seemed unrelated to age, sex, aetiology, or degree of pancytopenia. It was their opinion that the drug should always be given a minimum trial period of 3 months (Sánchez-Medal et al., 1964). Our patient at no time showed any evidence of haemopoietic stimulation to either of the above drugs, although he had had less than 2 months on oxymetholone at the time of his death.

Interest in this case lies mainly in the fact that the coexistence of two uncommon conditions in the same patient leads to conjecture regarding a possible aetiological association, although there is no way in which this can be proven.

\section{Acknowledgment}

We would like to thank Dr James Innes for permission to report this case, and for helpful criticism during its preparation.

\section{References}

Allen, D.M., Fine, M.H., Necheles, T.F. \& Dameshek, W. (1968) Oxymetholone therapy in aplastic anaemia. Blood, 32, 83.

ANDERSON, W. (1967) Pathology for the Surgeon. W. B. Saunders, Philadelphia and London.

BAKER, G.P. \& Oliver, R.A. (1965) Phytohaemagglutinin in the treatment of aplastic anaemia. Lancet, $\mathbf{i}, 438$.
BANERJEe, R.N. \& NARANY, R.M. (1967) Haematological changes in malignancy. British Journal of Haematology, 13, 829.

Catovsky, D. \& Sforza, M.C. (1967) Phytohaemagglutinin in aplastic anaemia. Lancet, ii, 991.

Cooper, E.H., Barkhan, P. \& Hale, A.J. (1963) Observations on the proliferation of human leucocytes cultured with phytohaemagglutinin. British Journal of Haematology, 9, 101 .

De Gruchy, G.C. (1968) Clinical Haematology in Medical Practice. Blackwell Scientific Publications, Oxford.

EHRLICH, P. (1888) Uber einen fall von anäemie mit bemkungun über regenerative veränderungun des knochenmaks. Charité-Annalen, 13, 300.

FURNHJELM, V. \& EKLUND, J. (1966) Treatment of aplastic anaemia with anabolic steroids and corticosteroids. Annales paediatrici Fenniae, 12, 89.

Grunewald, H., Taub, R.N., Wong, F.M., Kiossoblow, K.A. \& DAmesheK, W. (1965) Phytohaemagglutinin in treatment of aplastic anaemia. Lancet, i, 962.

HAYES, D.M. \& SPURR, C.L. (1966) Use of phytohaemagglutinin to stimulate haemopoiesis in humans. Blood, 27, 78.

Humble, J.G. (1963) In vivo action of phytohaemagglutin in severe human aplastic anaemia. Nature, 198, 1313.

Humble, J.G. (1964) The treatment of aplastic anaemia with phytohaemagglutinin. Lancet, 1, 1345.

LEWIS, S.M. (1965) Course and prognosis in aplastic anaemia. British Medical Journal, 5441, 1027.

MohleR, D.N. \& Leavell, B.S. (1958) Aplastic anaemia. An analysis of fifty cases. Annals of Internal Medicine, 49, 326.

Nowell, P.C. (1960) Phytohaemagglutinin. An initiator of mitosis in cultures of normal human leucocytes. Cancer Research, 20, 462.

Retief, F.B., WASSERMANN, H.P. \& Hofmeyer, N.G. (1964) Phytohaemagglutinin in aplastic anaemia. Lancet, $2,1343$.

Sanchez-Medal, L., Pizzuto, J., Torre-Lopez, E. \& DERBZ, R. (1964) Effect of oxymetholone in refractory anaemia. Archives of Internal Medicine, 113, 721.

Sánchez-medal, L., Gômez-Leal, A. \& Duarte-Zapata, L. (1966) Anabolic therapy in aplastic anaemia. Blood, 28, 979.

Scott, J.L., Cartwright, G.E. \& Wintrobe, N.M. (1959) Acquired aplastic anaemia. An analysis of thirty-nine cases and review of the literature. Medicine, 38, 119.

SILINK, S.J. \& FIRKIN, B.G. (1968) An analysis of hypoplastic anaemia with special reference to the use of oxymetholone in its therapy. Australasian Annals of Medicine, 17, 224.

VinCENT, P.C. \& DE Gruchy, G.C.(1967) Complications and treatment of acquired aplastic anaemia. British Journal of Haematology, 13, 977.

Willis, R.A. (1967) Pathology of Tumours. Butterworth, London. 